\title{
Best Practices for Endoscopic Procedures in Covid-19 Pandemic
}

\author{
Bhavna Shrirang Pate ${ }^{1}$, Meenakshi Eknath Yeola², Atul Gawande ${ }^{3}$, Amit Kumar Singh ${ }^{4}$, Harshal Atul Tayade ${ }^{5}$ \\ 1, 2, 4, 5 Department of Surgery, Jawaharlal Nehru Medical College, DMIMS, DU, Sawangi \\ (Meghe), Wardha, Maharashtra, India. ${ }^{3}$ Department of Gastro-Enterology, Jawaharlal Nehru \\ Medical College, DMIMS, DU, Sawangi (Meghe), Wardha, Maharashtra, India.
}

\section{ABSTRACT}

The corona pandemic has affected the health system of whole world. In India, this potentially long winding pandemic is overwhelming the capacity of outpatient and inpatient facilities, emergency as well as high dependency units of hospitals lead to severe shortage of resources, beds and staff. This has resulted in compromise in patient safety and outcomes. Endoscopic procedures have diagnostic as well as therapeutic importance and can aid in settling down acute illness following which definitive surgery can be planned later. Being aerosol generating procedures (AGPs), safe practices need to be adopted at both institutional and personal level.

There is tremendous impact on health care settings due to the COVID-19 situation in a very short span of time. In this COVID-19 pandemic scenario, while performing flexible endoscopic procedures. Elective endoscopies should be stopped. Flexible endoscopic and therapeutic interventions to be done only when absolutely necessary emergency and urgent cases. Proper PPE kits and N95 masks should be provided to all involved personnel in every endoscopic procedure. All patients undergoing emergency procedures should be considered Covid-19 positive and treated accordingly with every precaution to avoid infection transmission. Comprehensive and well-designed written-informed consent with inclusion of all necessary information of the Covid-19 situation should be taken from the patient and relative before all endoscopies. Urgent and Emergency endoscopic procedures must preferably be done under GA with very careful endotracheal intubation. High level of disinfection is required in endoscopies and the accessories used should either be disposable or thoroughly sterilized if reusable. As the fight against COVID-19 pandemic seems to be long-lasting we have to learn to live with it, prioritise resources and facilities keeping in mind patient needs in endoscopy departments. Protocols need to be introduced to encourage "new best practises" in the Endoscopy Department to ensure successful preventive measures against COVID-19 infection. This article addresses best practices to be followed and our experience of gastrointestinal endoscopy procedures during ongoing COVID-19 pandemic.

\section{KEY WORDS}

Covid-19, Endoscopy, Protocols, Pandemic, Triage.
Corresponding Author: Dr. Meenakshi Eknath Yeola, Department of Surgery, Jawaharlal Nehru Medical College, DMIMS, DU, Sawangi (Meghe), Wardha, Maharashtra, India. E-mail: drmeenu7@rediffmail.com

DOI: $10.14260 / j e m d s / 2020 / 825$

How to Cite This Article:

Pate BS, Yeola ME, Gawande A, et al. Best practices for endoscopic procedures in covid-19 pandemic. J Evolution Med Dent Sci 2020;9(49):3760-3766, DOI: $10.14260 /$ jemds/2020/825

Submission 18-07-2020,

Peer Review 19-10-2020,

Acceptance 26-10-2020,

Published 07-12-2020.

Copyright (C) 2020 Bhavna Shrirang Pate et al. This is an open access article distributed under Creative Commons Attribution License [Attribution 4.0 International (CC BY 4.0)] 


\section{BACKGROUND}

COVID-19 has spread exponentially throughout the world, with 34,838,209 confirmed cases and 1,033,356 deaths till date ${ }^{1}$ affecting both developed and developing countries with community spread seen in many countries afflicted with the virus. The propensity of spread of the virus has affected the health care systems and overwhelmed health care institutes leading to flooding of hospitals and intensive care units with COVID-19 patients. This has adversely affected the care related to non COVID disorders including surgical illnesses. Frontline health workers are getting exposed / quarantined, leading to sudden reduction in the available workforce. Non availability of public transport due to lockdowns, fear of infection transmission and diminished health work force has resulted in problems of access to care and quality of care. Various recommendations have been given by WHO and Surgical organizations around the world, to stop non emergent elective procedures, thus upsetting routine clinical practices and availability of care.

However, certain procedures if delayed may lead to progression of disease, prolonged hospital stay, increased morbidity and mortality due to unavailability of hospital services especially in rural set-ups further increasing the risk of COVID infection. Upper and lower gastrointestinal endoscopy has played a significant role in diagnosis and treatment of various surgical and medical illnesses, however in this COVID era, dilemma exists regarding performance of these invasive procedures as these are aerosol generating procedures (AGPs). ${ }^{2}$ This article addresses the best practices to be implemented in Endoscopy department in ameliorating elective, semi-emergent and emergent surgical and medical conditions in context of present COVID-19 Pandemic.

The following sections provide a detailed outline of Endoscopy protocols to in a view to decrease the risk of corona transmissions in Healthcare set ups,

The following four key areas are the main strategy for control of SARS-Cov-2 Infection: (1) pre-interventional (2) during intervention (3) after procedure and (4) After procedure leaving the facility.

\section{PRE-PROCEDURE PROTOCOLS}

\section{Consent Directives}

- An improvised and detailed consent with all the necessary COVID-19 information and all of its associated risks needs to be taken

- $\quad$ Pre-procedure COVID-19 tests are paramount.

- Post-operative mortality is significantly higher i.e. up-to $20 \%$ in COVID positive patients taken for surgery at elective or emergency basis ${ }^{2}$

\section{Categorization of Patients to Stratify Risk of COVID-19 Transmission}

To keep the infection spread to minimum, all patients with any suspected signs like breathlessness, fever, cough or positive travel history should be treated positive until a confirmed lab report is obtained. Strict protocols and clearly defined pathways need to be made available to all healthcare personnel involved in patient care. ${ }^{3}$

\section{Screening before Endoscopy}

Patients posted for endoscopy can be splitted in three divisions as per risk of Covid-19 infection:

\section{Mild-Risk}

- Asymptomatic (no cough, raised body temperature, shortness of breath, and diarrhoea).

- $\quad$ Not visited (in high-risk regions* in the past 2 weeks)

- No history of contact (with a Corona cases)

\section{Intermediate-Risk}

- Symptomatic

- $\quad$ visited (in high-risk areas* in the past 14 days) AND

- history of contact (with a COVID-19)

or

- Asymptomatic but

- history of contact (with a COVID-19 OR

- $\quad$ visited high-risk regions* in the past 2 weeks)

\section{High-Risk}

- At the minimum single symptom present AND

- Contact with a Corona cases OR

- $\quad$ visited in a high-risk region

\section{$N B$}

"High-risk" regions are those regions where more than thousand patients have become positive till date; but it is upgrading continuously day to day.

All urgent lifesaving interventions can be called as "high-risk" if patient history is not possible to evaluate and doubtful.

\section{PRE-OPERATIVE ASSESSMENT}

Assessment should include detailed history about prior travel to any region with high number of infected COVID-19 cases, containment zones, contact with any COVID-19 case or history of fever, cough, body aches, breathlessness, upper respiratory tract infection. RT-PCR / ELISA tests for COVID-19 should be done. All due precautions should be taken considering every patient as potentially infected until and unless proven. ${ }^{4}$ All cases must undergo RT PCR or rapid antigen testing classified as per risk transmission prior to endoscopy.

As per WHO, a patient of COVID-19 can be defined as a he or she have positive laboratory evidence of COVID-19 infection with or without clinical presentation. A doughtfull case if testing is inconclusive is called as a probable.5,6 There are three criteria to define a patient as a suspected case: (1) case with acute respiratory illness with no other etiology and a history of travel to, or resident in, countries reporting local transmission of COVID-19 during 14 days before illnesss; (2) cases with acute respiratory disease and having contact with a confirmed or probable case of COVID-19 in the past 14 days before onset of disease and (3) patients with severe acute respiratory infection 
needed admission for treatment and with no other aetiology that fully support the clinical presentation.5,6

All patients need to undergo pre-screening before arrival at the endoscopy centre and the below given full information should be gathered as per capacity of centre. : temperature greater than $37.5 \mathrm{C}$ or $99.5 \mathrm{~F}(\mathrm{~F})$; (2) history of journey (T); (3) heath care as a occupation (O); (4) contact history (C); (5) clustering (C) (FTOCC) ${ }^{6,7}$ The history of travelling must include all recent visits in the past 14 days to countries with a high evidence of COVID-19. Persons who's having occupation in healthcare and research laboratory with processing specimens of Covid 19 are defined as occupational exposure. Contact History includes close contact with confirmed COVID-19 patients in the last 14 days or travel to high-risk countries in the past 14 days. Clustering is defined as two or more confirmed COVID-19 positive patients with a close contact history. Oneor more than onepositivecriteriaforFTOCC isregarded as a clinically suspected case, and COVID-19 testing is to be done prior to any endoscopic procedure. Clinical indication for every suspected, probable or confirmed COVID-19 cases should be reviewed, and only emergency or life-threatening indications should undergo endoscopy.

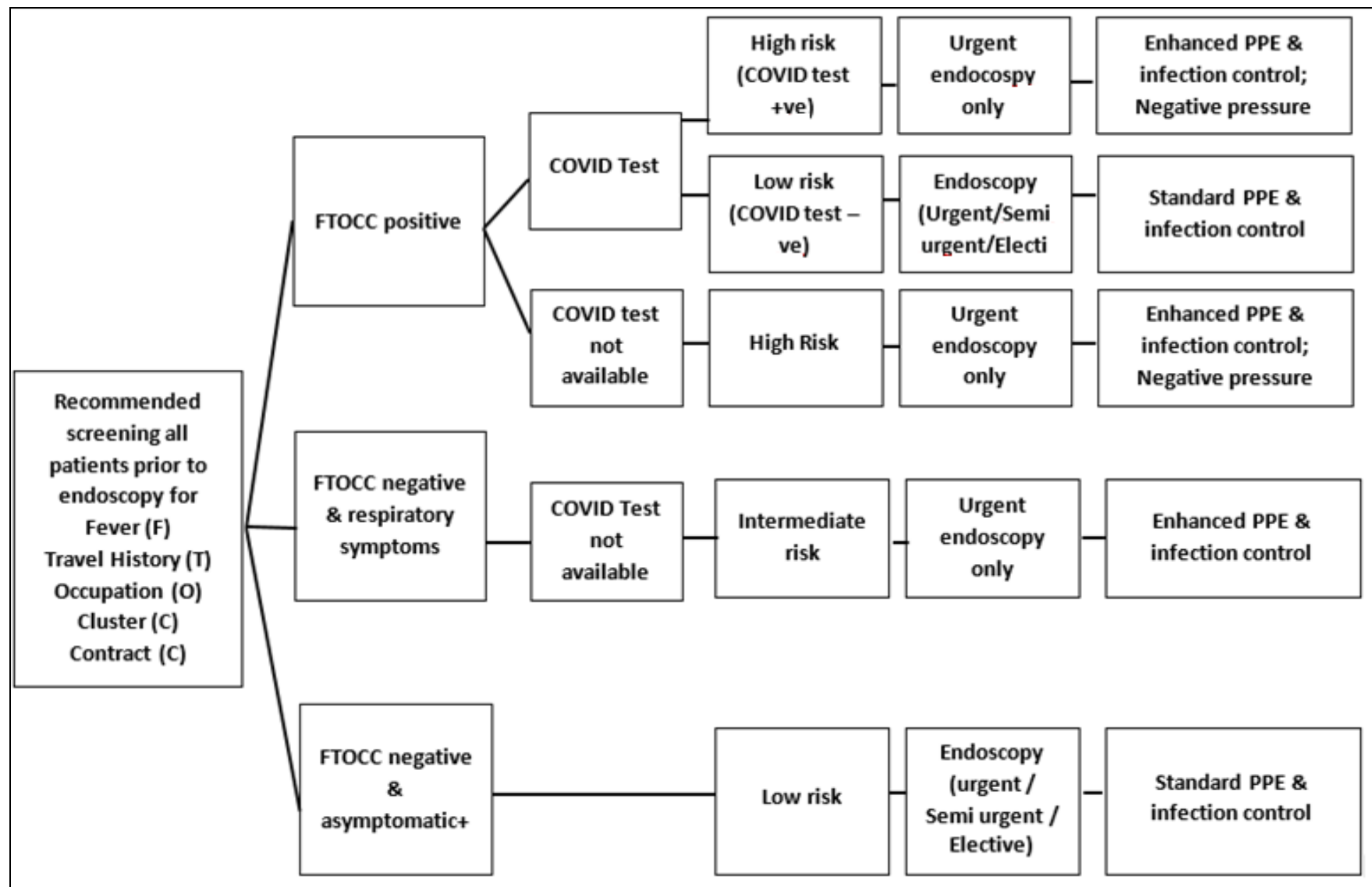

Flowchart 1: Screening of Patients Prior to Endoscopy

- Flow chart describing the protocol to screen before endoscopy and triage for endoscopy during COVID-19 pandemic.

- $\quad$ PPE-personal protective equipment.6

- During the COVID-19 pandemic endoscopic procedures have been grouped as urgent, semi-urgent and elective.

\section{Procedures Included}

1. Urgent endoscopy

2. Gastrointestinal bleed, acute

3. Management of perforations and leakage

4. Biliary sepsis

5. Foreign body

6. Gastrointestinal obstruction requiring stenting

7. Gl access for urgent feeding

8. Chollangitis, Choledocolithiasis

9. GI Perforation

\section{Semi-Urgent Endoscopy}

(to Be Discussed on a Case-by-Case Basis)

- Endoscopic treatment for gastrointestinal neoplasia (Endoscopic Mucosal Resection / Endoscopic submucosal dissection)

- Endoscopy for highly suspicious case of cancer

- Small bowel enteroscopy for occult GI bleeding

- Gastro-intestinal cancers-diagnosis and staging

- Draining of Malignant Biliary Obstruction

- High grade dysplasia or Early intra-mucosal cancer oesophagus

- Stomach or large colonic polyps at high-risk of submucosal invasion

- Nutritional support by nasojejunal (NJ) tube / percutaneous endoscopic gastrostomy (PEG) placement

- Stenting for malignant luminal obstruction (growth in the oesophagus, colon and duodenum)

- Upper GI bleeding without hemodynamic instability

- Colonoscopy for melena after negative upper GI endoscopy 
- Severe Anaemia with no hemodynamic instability

- Foreign body in the stomach

- $\quad$ Lymph node EUS sampling

- Benign stricture requiring dilation / stenting

- Necrosectomy

\begin{tabular}{|c|c|c|}
\hline & ASGE & BSG \\
\hline \multicolumn{3}{|l|}{ Gastrointestinal haemorrhage } \\
\hline Upper Gastrointestinal haemorrhage & Urgent & \\
\hline Lower Gastrointestinal haemorrhage & Urgent & Urgent if ongoing \\
\hline Anaemia due to iron loss & $\begin{array}{l}\text { If situation } \\
\text { demands }\end{array}$ & \\
\hline $\begin{array}{l}\text { Oesophageal varices treatment by banding, glue } \\
\text { or sclerotherapy (secondary prevention) }\end{array}$ & \multicolumn{2}{|c|}{ If situation demands } \\
\hline Bolus impaction / foreign bodies & \multicolumn{2}{|r|}{ Urgent } \\
\hline Symptoms & & \\
\hline Non-alarm symptoms & \multicolumn{2}{|l|}{ Not Urgent } \\
\hline Alarm symptoms & \multirow{2}{*}{\multicolumn{2}{|c|}{$\begin{array}{c}\text { Not given If situation demands }{ }^{9} \\
\text { If significantly affect oral intake, it is } \\
\text { urgent }\end{array}$}} \\
\hline Difficulty in swallowing & & \\
\hline \multicolumn{3}{|c|}{ 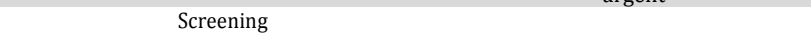 } \\
\hline Oesophagogastroduodenoscopy & Not Urgent & - \\
\hline Screening / surveillance colonoscopy & Not Urgent & - \\
\hline $\begin{array}{l}\text { Surveillance/ treatment of premalignant or } \\
\text { malignant lesions }\end{array}$ & Urgent & - \\
\hline Low-risk follow-up (esophagitis / ulcer healing) & NA & Not Urgent \\
\hline Surveillance of Barrett's / varices & NA & Not Urgent \\
\hline $\begin{array}{c}\text { Sub-mucosal lesions, pancreatic cysts non- } \\
\text { high risk }\end{array}$ & NA & $\begin{array}{l}\text { Not Urgent } \\
\text { endoscopic } \\
\text { ultrasound }\end{array}$ \\
\hline Inflammatory bowel disease (general) & $\begin{array}{l}\text { Urgent if affect } \\
\text { treatment }\end{array}$ & 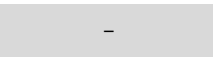 \\
\hline New suspected acute colitis & NA & Case-by-case \\
\hline Disease assessment & $\begin{array}{l}\text { Urgent if affect } \\
\text { treatment }\end{array}$ & Not Urgent \\
\hline $\begin{array}{l}\text { Therapeutic procedures / others Planned } \\
\text { EMR/ESD for high-risk lesions }\end{array}$ & NA & If situation demands \\
\hline $\begin{array}{l}\text { Nutrition support (urgent inpatient PEG / NJ } \\
\text { tube) }\end{array}$ & NA & Urgent \\
\hline $\begin{array}{c}\text { Therapy of perforations / leaks (including } \\
\text { vacuum therapy) }\end{array}$ & NA & Urgent \\
\hline Palliation of GI obstruction (includes biliary) & \multicolumn{2}{|c|}{ Urgent } \\
\hline Cholangitis & \multicolumn{2}{|c|}{ Urgent ERCP } \\
\hline Symptomatic pancreatic biliary disease & \multicolumn{2}{|c|}{ Urgent drainage } \\
\hline $\begin{array}{l}\text { Elective therapeutic procedures (stricture } \\
\text { dilation, RFA, POEM, pneumatic dilation, } \\
\text { ampullectomy) }\end{array}$ & NA & Not Urgent \\
\hline EUS for cancer staging / treatment planning & Urgent & $\begin{array}{l}\text { If situation demands } \\
\text { (if significantly affect } \\
\text { treatment) }\end{array}$ \\
\hline Table 1: Indication for $E$ & scopic Pro & edures \\
\hline
\end{tabular}

\section{Elective Endoscopy}

\section{(Deferred Until Further Notice)}

- All routine diagnostic endoscopy

- All surveillance and follow-up endoscopy (Barrett's oesophagus / polyp /

- IBD / gastric intestinal metaplasia / history of Gl cancer)

- Therapeutic endoscopy for non-cancer disease

- Other ERCP cases-asymptomatic stones; therapy for chronic pancreatitis;

- Metal stent removal / change; ampullectomy follow-up

- EUS for diagnosis of benign condition

- $\quad$ ERCP for non-malignant conditions

- Endoscopic therapy for benign GI disorders (bariatric, GORD)

- Dyspepsia without alarm symptoms

- Gastro-oesophageal reflux disease (GERD)

- Irritable bowel syndrome (IBS))

- Barrett's oesophagus

- Inflammatory bowel syndrome (IBD)

- Post-endoscopy resection
- Bariatric Gl endoscopy procedures (e.g., intra-gastric balloons and endoscopic sleeve gastroplasty)

Elective endoscopy procedures can be planned later when the risk of transmission of COVID-19 virus at endoscopy considerably declines or unless patients' symptoms remarkably deteriorate in the intervening period.

[Recommendations by American Society of Gastrointestinal Endoscopy (ASGE) and, British Society of Gastroenterology $(\mathrm{BSG})]^{8}$

\section{Reorganization of the Procedure Room}

- Reorganization of the procedure room is required to control the COVID-19 transmission.

- $\quad$ Traffic the procedure room should be limited ${ }^{3}$

- Staggering arrangement of operative procedures.

- No observers or visitors allowed in OT.

- Minimum health care personnel in the procedure room during anaesthesia.

- Controlled smoke (aerosol) evacuations-suggestions are still dynamic.

- Minimise number of health care worker in the theatre area to the least needed during the procedure

- Required personal protective equipment should be given to all staff of the endoscopy team depend on the risk classification. ${ }^{9}$

- $\quad$ Enough hand sanitisation pre and after handling patients must be advised for all staff of endoscopy unit. ${ }^{9}$

- $\quad$ Disposable Endoscopic accessories are preferably used ${ }^{9}$

- Furniture kept in the room at the minimum ${ }^{9}$

- $\quad$ Single person is allowed to use computer to for data entry, communication, etc. if possible ${ }^{9}$

\section{Patient Transport}

For patient transport, pre-defined direct shortest possible route which is far from other patients and general public should be followed in the hospital premises to keep the chances of infection to minimum. Trained Personnel with appropriate PPE kits should be available for patient transfer.

\section{Operative Personnel}

Minimum number of health care workers should be present inside the operating area. Every person should be aware of possible risks of COVID-19 transmission and adequate precautions should be taken. Procedure room should not be left by the personnel who are involved in the intervention. ${ }^{4}$

\section{Endoscopy Department Preparation}

Minimize the equipment in the procedure room to strictly and depends on demand of situation. On the initiation of the intervention, best efforts should be made to use the available equipment in the procedure room, thus minimising the staff transition in the OT room. Replacement of standard Anaesthetic trolley with pre-prepared dedicated trolleys on a case-to-case basis with minimum but optimal stock. Alcohol based hand disinfectants should be available for proper hygiene. ${ }^{3}$ 


\section{PPE (Personal Protection Equipment)}

All operators (i.e., endoscopist, anaesthetist, nurses, and technicians) must make use of appropriate PPE before coming in contact with the infected or suspected patient. Hand hygiene is to be maintained and Full PPE kit is to be used by the patient's received personnel inside the COA filter area

\section{PPE Includes}

FFP2 facial mask, FFP3 facial mask (in case of manoeuvres at high risk of generating aerosolized particles), Disposable double pair of nitrile gloves, gowns, Use and discard long sleeve waterproof aprons, protective visors or face shields, disposable long shoe covers, disposable head caps, alcoholic disinfectant solution. ${ }^{3}$

\begin{tabular}{|c|c|c|}
\hline Setting & & PPE Suggested ${ }^{a}$ \\
\hline $\begin{array}{l}\text { Staff not in contact } \\
\text { with patients }\end{array}$ & $\begin{array}{c}\text { - Administrative } \\
\text { personnel } \\
\text { - Others }\end{array}$ & Surgical mask \\
\hline $\begin{array}{l}\text { HCW in contact with } \\
\text { patients outside } \\
\text { endoscopy room }\end{array}$ & $\begin{array}{c}\text { - Admitting nurse } \\
\text { - Recovery room } \\
\text { personnel }\end{array}$ & $\begin{array}{c}\text { Surgical mask (Hairnet) } \\
\text { Eye protection (face shield or goggles) } \\
\text { Gloves } \\
\text { Long-sleeve gown }\end{array}$ \\
\hline $\begin{array}{l}\text { staff in the endoscopy } \\
\text { room of COVID } \\
\text { negative patients }\end{array}$ & $\begin{array}{lc}-\quad \text { Endoscopy MD } \\
-\quad \text { Endoscopy nurse } \\
-\quad \text { Anaesthesia team }\end{array}$ & $\begin{array}{c}\text { Hairnet with Surgical mask } \\
\text { Respirator mask (filteringfacepiece 2) } \\
\text { Eye protection (face shield preferred) } \\
\text { Double pair of gloves } \\
\text { Long-sleeve fluid-resistant gown or gown } \\
\text { plus apron Clogs with protection }\end{array}$ \\
\hline $\begin{array}{l}\text { health careworker in } \\
\text { the endoscopy room } \\
\text { of suspected or } \\
\text { confirmed COVID } \\
\text { patients (if possible in } \\
\text { a negative pressure } \\
\text { room) } \\
\end{array}$ & $\begin{array}{l}\text { - Endoscopy MD } \\
\text { - Endoscopy nurse } \\
\text { - } \quad \text { Anaesthesia team }\end{array}$ & $\begin{array}{c}\text { Good quality hairnet } \\
\text { Respirator mask (filteringfacepiece } 3 \text { / } \\
2)^{\mathrm{b}} \\
\text { Face shield } \\
\text { Double pair of gloves } \\
\text { Long-sleeve fluid resistant gown Clogs } \\
\text { with leg protection } \\
\end{array}$ \\
\hline \multicolumn{3}{|c|}{ Reuse of Mask not Recommended } \\
\hline \multicolumn{3}{|c|}{ Table 2: Recommendations of PPE According to Level of Exposure ${ }^{8}$} \\
\hline
\end{tabular}

\section{Anaesthesia Protocols}

Intubation during administration of general anaesthesia (GA) results in aerosolisation, putting the anaesthesia team and OT personnel at risk. Hence, if a procedure can be done under local / regional anaesthesia, short GA or with sedation, it should be given preference. ${ }^{4}$ For intubation and other anaesthesia practices, the guidelines issued by anaesthesia and Airway Societies should be followed. ${ }^{5}$

\section{Points to Be Noted in General}

- A time lapse of at least 1 hour must be given between 2 consecutive procedures. 30 minutes for deep cleaning and 30 minutes for UV sterilization.

- In Procedure Room Donning and Doffing in the Wash area of the PPE should be practiced

- Post procedure all equipment should be cleaned with $1 \%$ sodium hypochlorite solution.

\section{Intubation Protocols}

- $\quad$ Full body PPE kit to be worn along with N95 mask and Face Shield.

- Video laryngoscope to be used for Intubation.

- N95 mask not to be reused in this case.

- AC or laminar flow not to start before completion of intubation procedure.

- If needed and possible, intubation and extubation to be done within room with negative pressure
- All contaminated material, which needed to be reused (e.g. video laryngoscope device) to be immediately kept in separate bag for sterilization.

- Use bacterial / viral filter (e.g. HEPA of Portex) only. No HME filter to be used.

- Create a hood over patient head while doing airway procedure if feasible.

- Avoid positive pressure ventilation before intubation if possible. Use rapid acting muscle relaxant (e.g succinylcholine) for intubation.

- Extubation shall be done with same level of precaution as intubation. Minimize coughing while extubation. Stop laminar airflow (20 min prior) or AC before extubation.

\section{INTRA OPERATIVE PROTOCOLS ${ }^{3}$}

- The procedure room door is to be kept closed throughout the procedure.

- $\quad$ Material and equipment supply during the procedure into the endoscopy room must be strongly discouraged. Beforehand anticipation of what might be required during the procedure should be done by the scrub nurse and the endoscopist.

- $\quad$ During intubation, minimum personnel should be there in the procedure room. The team should wait outside till intubation has been done.

- Once inside the procedure room, the personnel should not leave until the end of procedure.

- $\quad$ To keep the charring of tissues and thereby creation of smoke to minimum, electro-cautry should be avoided or used at the lowest possible setting. Smoke evacuator / Suction devices should be used to evacuate excessive smoke and aerosols, when electro-cautery is used. ${ }^{6}$

- $\quad$ Post-procedure cleaning and disinfection is to be done of all areas with possible contamination. Best Efforts to reduce the risk of contamination with biopsy procedures for histopathology should be made.

- Intubation during induction of general anaesthesia almost always leads in aerosolisation, putting the anaesthesia team and OT personnel at risk. Hence, if a procedure can be done under local / regional anaesthesia, short GA or with sedation, it should be given preference. ${ }^{4}$

- For intubation and other anaesthesia practices, the guidelines issued by anaesthesia and Airway Societies should be followed.

\section{POST PROCEDURE PROTOCOLS 3}

Proper removal of the PPE and its safe disposal should be done. After removing PPE, no one should enter the procedure room till it has been cleaned and sterilized with $1 \%$, hypochlorite solution.

- Personnel who are not carry out the patient care directly must left the procedure room at the coplition of case and remove all protective gear in the special wash area for doffing as per the standard sequence as described below. Only after the doffing is complete, clean area should be assessed. 
- $\quad$ Patient transferring personnel should wear appropriate PPE and follow specific access routes.

\section{Instructions for Doffing of PPE 3}

Care is to be taken to avoid getting infected while removal of PPE. A standard procedure is to be followed that prevents the recontamination of operators' hands and clothes. The outer gloves are the most contaminated part and should be removed firstly. Every other part of the PPE is to be considered infected and care should be taken while removal, especially if positive symptoms like cough are present in the patient. Subsequent removal of protective gown / suite, shoe cover, and head cap should be done. Glasses and masks should then be removed, with special care while handling the masks with the ear laces without any contact to its external side. Lastly the second pair of gloves is to be removed and alcohol-based hand hygiene solution should be used immediately. ${ }^{7}$

In the endoscopy room, equipment and instruments should be considered as potentially infected and adequate cleaning and sterilization of the same should be done before posting another case. Removal and disposal of PPE must be done outside the Operation Theatre in the wash areas dedicated for doffing to avoid the virus transmission to the healthcare personnel. Dedicated container for hazardous and infected biomedical waste should always be available outside the endoscopy room to immediately and effectively dispose off all the infected material and PPE kits. Before transfer to collection points, these containers must be properly sealed. On the initiation of the intervention, best efforts should be made to use the available equipment in the procedure room, thus minimising the staff transition in the OT room. Replacement of standard Anaesthetic trolley with pre-prepared dedicated trolleys on a case-to-case basis with minimum but optimal stock. Alcohol based hand disinfectants should be available for proper sanitisation.

\section{AFTER PROCEDURE / LEAVING THE ENDOSCOPY ROOM}

- Scrub clothes that were worn on arrival at hospital to be removed as soon as separated from the patient.

- Consider taking a shower before changing into clean scrubs or home clothes.

- Social distancing should be maintained. Hands should be washed regularly.

\section{AFTER LEAVING THE HOSPITAL ${ }^{8}$}

- Frequently clean your mobile phones before, during, as well as after the health care activities. Mobile phones can be placed in Ziploc bags while in the hospital. Thus allowing the use of cell phones during work.

- Upon arrival at home, remove all clothes and keep it at separate location for laundry

- Reduce physical contact with family members as much as possible and practice frequent hand washing.

- Hard surface areas at home should be cleaned with effective alcohol-based solution (e.g., $60 \%$ alcohol).

\section{OUR EXPERIENCE}

Acarya Vinoba Bhave Rural Hospital is Tertiary care rural hospital located in Central India in which 300 beds are designated to COVID care. Following is the experience of procedures done during January 2020 till June 2020 in Endoscopy department. All the protocols were followed strictly for all procedures and post procedure period was uneventful.

\begin{tabular}{|cccccccc|}
\hline $\begin{array}{c}\text { Procedure } \\
\text { Name }\end{array}$ & Jan. & Feb. & March & April & May & June & Total \\
Endoscopy & 112 & 113 & 77 & 15 & 13 & 43 & 373 \\
Coloscopy & 14 & 12 & 23 & 03 & 07 & 08 & 67 \\
Sigmoidoscopy & 00 & 01 & 00 & 00 & 00 & 01 & 02 \\
Dilatation & 03 & 00 & 02 & 01 & 00 & 00 & 06 \\
Banding & 02 & 11 & 10 & 01 & 02 & 02 & 28 \\
ERCP & 05 & 13 & 07 & 02 & 01 & 04 & 32 \\
Hemoclip & 01 & 01 & 00 & 00 & 00 & 01 & 03 \\
Placement & 00 & 00 & 00 & 00 & 00 & 02 & 02 \\
Glue Injection & 00 & 01 & 00 & 00 & 00 & 00 & 01 \\
Oesophageal & 00 & $\mathbf{1 5 2}$ & $\mathbf{1 1 9}$ & $\mathbf{2 2}$ & $\mathbf{2 3}$ & $\mathbf{6 1}$ & $\mathbf{5 1 4}$ \\
Stenting & $\mathbf{1 3 7}$ & $\mathbf{1 5 2}$ & \multicolumn{7}{c}{} \\
\hline Total & Table 3. Endoscopic Procedures from Jan 2020 to June 2020 \\
\hline
\end{tabular}

\section{DISCUSSION}

There is tremendous impact on health care settings due to the COVID-19 situation in a very short span of time. In this COVID19 pandemic scenario, while performing flexible endoscopic procedures, following safe endoscopy practice guidelines as per the respective governing society is essential. ${ }^{7}$

- Elective endoscopies should be stopped. Flexible endoscopic and therapeutic interventions to be done only when absolutely necessary emergency and urgent cases.

- $\quad$ Proper PPE kits and N95 masks should be provided to all involved personnel in every endoscopic procedure.

- All patients undergoing emergency procedures should be considered Covid-19 positive and treated accordingly with every precaution to avoid infection transmission.

- Comprehensive and well-designed written-informed consent with inclusion of all necessary information of the Covid-19 situation should be taken from the patient and relative before all endoscopies.

- Urgent and Emergency endoscopic procedures must preferably be done under GA with very careful endotracheal intubation.

- High level of disinfection is required in endoscopies and the accessories used should either be disposable or thoroughly sterilized if reusable.

\section{Operating Room Directives ${ }^{7}$}

1. Wherever possible, Negative Pressure room should be used

2. Minimize the number of HealthCare Workers in the procedure room

3. Minimize the number of personnel in the surgical team

4. Limit the personnel transition in and out of the procedure room until the intervention is complete

5. At least 60 minutes interval between two interventions.

6. Efforts should be taken to reduce the duration of the procedure to minimum

a. Avoid training of Nursing or Surgical personnel 
b. Avoid multiple procedures and complex interventions

7. Cleaning and disinfection of reusable accessories with effective solutions at the end of the procedure

8. Recommendation of $1 \%$ sodium hypochlorite solution is given for procedure tables and equipment trolleys after the shifting of patient

9. All operators (i.e., endoscopist, anaesthetist, nurses, and technicians) must make use of appropriate PPE before coming in contact with the infected or suspected patient. Hand hygiene is to be maintained and Full PPE kit is to be used by the COVID-19 positive persons received in the COA filter area

10. Minimum number of health care workers should be present inside the operating area. Every person should be aware of possible risks of COVID-19 transmission and adequate precautions should be taken. Procedure room should not be left by the personnel who are involved in the intervention

Intubation during administration of general anaesthesia (GA) results in aerosolisation, putting the anaesthesia team and OT personnel at risk. Hence, if a procedure can be done under local / regional anaesthesia, short GA or with sedation, it should be given preference.

\section{CONCLUSIONS}

As the fight against COVID-19 pandemic seems to be longlasting we have to learn to live with it, prioritise resources and facilities keeping in mind patient needs in endoscopy departments. Robust mechanisms, protocols and strategies for prevention of Infection, proper triage, use of appropriate PPEs, and infrastructural modification while taking optimal care to protect the healthcare personnel as well as patients.

Financial or other competing interests: None.

Disclosure forms provided by the authors are available with the full text of this article at jemds.com.

\section{REFERENCES}

[1] Worldometer Coronavirus Pandemic 2020 [updated 03/10/2020], 07:13 GMT. https://www.worldometers.info/coronavirus/.

[2] Somashekhar S, Shivaram H, Abhaham SJ, et al. ASI's Consensus Guidelines: ABCs of What to do and what not during the COVID-19 pandemic. Indian J Surg 2020;82:240-50.

[3] Coccolini F, Perrone G, Chiarugi M, et al. Surgery in COVID19 patients: operational directives. World J of Emerg Surg 2020;15:25.

[4] Amasi I, Selsi. Inter Association Surgical Practice Recommendations in Covid 19 Era (for Minimal Access Surgeons in India) [Review Article]. 2020 [updated 23/04/2020. https://www.amasi.org/announcementsdetails.php?AnnouncementId=5f2cd65a9f2d294e554d9 $6 \mathrm{~b} 2$.

[5] WHO. Coronavirus disease (COVID-2019) situation reports. Situation report - 64, 2020. https://www.who.int/docs/defaultsource/coronaviruse/situation- reports/20200324sitrep-64-covid-19.pdf?sfvrsn=703b2c40_2.

[6] Chiu PWY, Ng SC, Inoue H, et al. Practice of endoscopy during COVID-19 pandemic: position statements of the Asian Pacific Society for Digestive Endoscopy (APSDECOVID statements). Gut 2020;69(6):991-6.

[7] Wong AT, Chen H, Liu SH, et al. From SARS to avian influenza preparedness in Hong Kong. Clin Infect Dis 2017;64(Suppl 2):S98-S104.

[8] Libânio D, Bastos P, Pimentel-Nunes P. Safe and valuable endoscopy in the COVID Era. GE Port J Gastroenterol 2020;27(4):219-23.

[9] Filho CEC, Castro R, Fernandes FF, et al. Gastrointestinal endoscopy during COVID-19 pandemic: an updated review of guidelines and statements from International and National Societies. Gastrointest Endosc 2020;92(2):440-5. 